\title{
The syntax of the addressee in imperatives: What Levantine Arabic attitude datives bring to the table
}

\author{
Youssef A. Haddad*
}

\begin{abstract}
The imperative subject constitutes a special category compared to the subjects of other types of clauses in that it is required to be the addressee. Zanuttini (2008) argues that this requirement follows from a special syntactic status: imperative subjects enter the computation with gender and number but no person features. They acquire a second-person specification later by entering an agreement relation with the head of a jussive phrase, a functional projection that is unique for imperative clauses and that occupies the left periphery. This paper provides independent evidence from attitude dative constructions in Levantine Arabic in support of this approach. Attitude datives are optional pronominal elements that make pragmatic contributions to utterances without altering their meaning. The paper shows that attitude datives whose referent coincides with the referent of the subject are less restricted in terms of the interpretation they may receive in imperative versus other types of clauses. Imperative clauses are more permissive, a characteristic that follows from the special status of their subject.
\end{abstract}

Keywords: Arabic; datives; imperatives; addressee; adjuncts; countercyclic merge; cyclic merge

1. The imperative subject: A brief overview. Imperative subjects are intriguing elements compared to the subjects of other types of clauses. One reason is that the subject of an imperative clause, unlike the subject of a declarative or interrogative clause, is required to be the addressee. This raises the question as to whether this discourse requirement follows from a special syntactic status of imperative subjects. In other words, is the syntactic representation of the imperative subject different from or on a par with the syntactic representation of subjects of other types of clauses? This question has received ample attention in the literature; see, for example, Platzack \& Rosengren (1998), Potsdam (1998), Rupp (1999, 2003). One proposal put forth by Zanuttini (2008) argues that the subject of imperative clauses is different from canonical subjects. To Zanuttini, the imperative subject enters the computation with number and gender but no person features. This view is supported by a cross-linguistic tendency for imperatives to show reduced morphology (Zhang 1990; Zanuttini 2008). Such reduction usually takes the form of lack of person marking, as observed by Mauck (2005; cited in Zanuttini 2008: 189: fn. 7). A case in point is Arabic. Imperatives in all Arabic varieties show reduced morphology. The verb shows gender and number but no person features. Observe the verb 'help' in (1) as it may be used in Syrian Arabic, as well as other Levantine Arabic varieties (Jordanian, Lebanese, and Palestinian Arabic). In the subjunctive form in (a), the verb shows gender, number, and person agreement. In the imperative/jussive form in (b), only the suffix, which carries gender and number agreement, is realized; the prefix, which carries person agreement, is absent.
a. Subjunctive:
t-sa:\{d-i: = 3-help-FEM.SG
b. Imperatives:
sa:Sd-i: = help-FEM.SG

If the subject of imperatives enters the computation without a person feature, how is the subject interpreted as an addressee? According to Zanuttini (2008), the subject is endowed with a

\footnotetext{
* Author: Youssef A. Haddad, University of Florida (yah@ufl.edu)
} 
second person or addressee feature by a jussive phrase, a functional projection that is unique for imperative clauses and that occupies the left periphery. If the jussive phrase is structurally closest to the subject, as in (2), "its head enters an agreement relation with the subject, that is, a syntactic relation that results in the same person feature appearing in both places (the jussive head and the subject)" (Zanuttini 2008: 196; see p. 204 and fn. 30 for more details about the nature of this relation). ${ }^{1}$

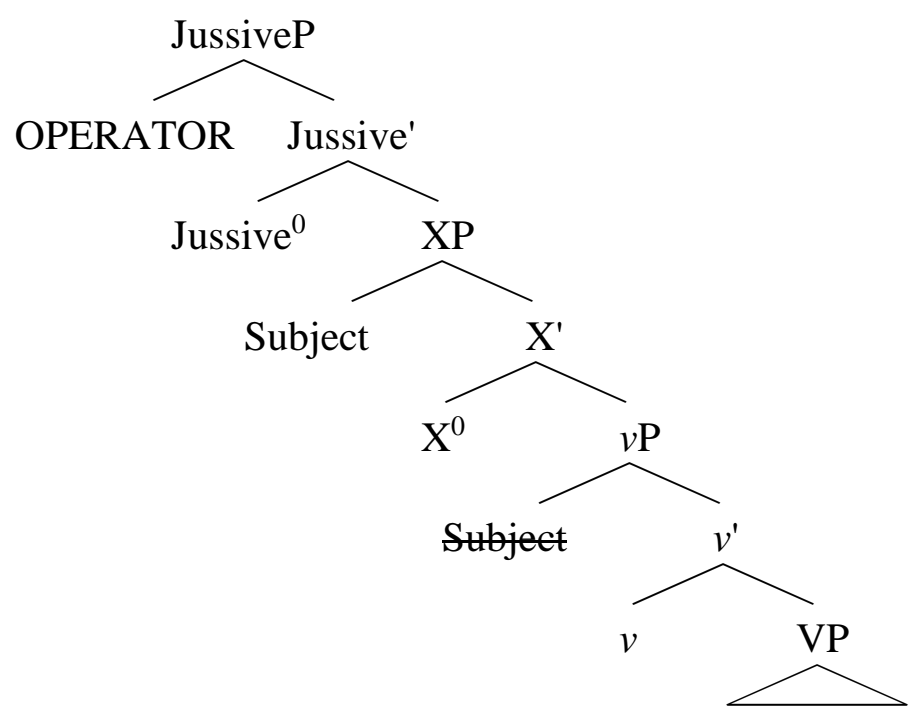

Zanuttini provides convincing evidence in support of her analysis of imperative subjects as lacking person specification and of the presence of an imperative-specific projection, which she labels as a jussive phrase, in the left periphery. In this paper, I present further evidence in favor of this approach from an independent phenomenon: Levantine Arabic attitude dative constructions. The paper is organized as follows. Section 2 provides an overview of attitude dative constructions in Levantine Arabic and presents a syntactic account of these structures based on Haddad (2014, 2019). The section also highlights a feature of subject-oriented attitude dative constructions that is relevant to the topic of imperatives. Section 3 focuses on attitude datives in imperative clauses. It starts with a prediction about such clauses based on Zanuttini's analysis and presents new data to show that the prediction is borne out. Except for the constructed examples in (4) and (9), all the Arabic data in sections 2 and 3 are attested utterances collected from social media - mainly twitter - and TV shows. Section 4 is a conclusion.

2. Attitude datives in Levantine Arabic. Attitude datives (ADs) are optional pronominal elements that may be inserted in utterances without altering their truth conditions. Personal datives in Appalachian English fit this description, as the sentences in (3) illustrate. The boldface pronouns him and me in (3) are personal datives. They are optional in the sense that they are not thematically linked to the events of looking for a house in (a) or finding a pretty card in (b), and thus the sentences have the same meaning or are true under the same conditions with or without these pronouns.

\footnotetext{
${ }^{1}$ Zanuttini assumes that an imperative clause consists of a number of functional projections. One of these projections could be TP, albeit a defective one that lacks phi features. However, since the presence of TP in imperative clauses is a controversial topic, and since resolving this issue is not immediately relevant to topic of addressee, Zanuttini labels this projections as XP instead. I do the same here.
} 
(3) a. He was looking to buy him a house for his family.

b. I want to find me a pretty card for my mother. (Christian 1991: 16; (12))

When inserted in utterances, the personal datives in (3), and ADs in general, do serve a pragmatic function. Haddad (2018) analyzes ADs in Levantine Arabic as interpersonal pragmatic markers that serve two functions: (i) an evaluative function toward events, behaviors, objects, or individual, and/or (ii) a relational function to manage (affirm, maintain, challenge, etc.) relationships between interlocutors. Four types of ADs are licensed in Levantine Arabic. These are speaker-, hearer-, topic/affectee-, and subject-oriented ADs, as (4) illustrates. ${ }^{2}$

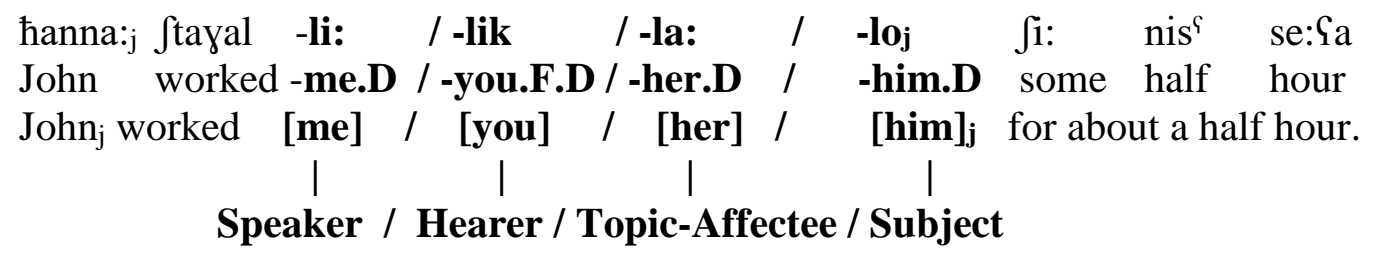

Only one AD may cliticize to a verb at a time. However, as many ADs as there are verbal elements may be inserted in an utterance. Each type of AD makes distinct pragmatic contributions. For example, speaker-oriented ADs normally portray the speaker as an authority figure in relation to the hearer or an event, while a hearer-oriented AD is often used as an attention grabber or as "an appeal for the hearer's empathy, assent, and/or shared experience, knowledge, and membership" (Haddad 2018: 101). These functions are illustrated in (5) and (6). The former is a tweet by a Syrian woman complaining about people who claim they know a thing or two about the civil war in Syria although they have not lived there or experienced the war firsthand. The tweet contributor employs a speaker-oriented AD to present herself as authority on the topic of Syria based on her experience as a resident of the country.

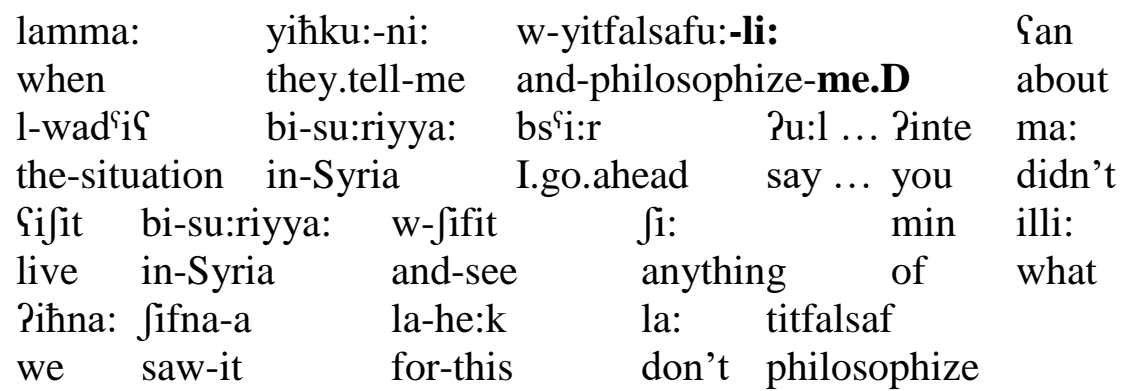

'When people start theorizing [me] about the situation in Syria, I tell them, "You have not lived in Syria or seen what we have seen. Therefore, quit theorizing.'

$$
\begin{aligned}
& \text { لما_يحكوني و يتفلسفولي عن الوضع بسوريا }
\end{aligned}
$$

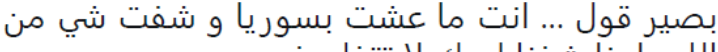

Example (6) is a tweet with two hearer-oriented ADs. The tweeter is fed up with fans of AlAhli Saudi soccer team who talk about national and international soccer as if they were experts. He reaches out to like-minded followers and twitter users who do not support Al-Ahli and do not

\footnotetext{
${ }^{2}$ Throughout this paper, I use the terms 'hearer,' 'reader,' and 'addressee' to refer to the ratified participant who is expected to receive the speaker's or writer's utterances. The terms also refer to the target, the individual(s) whose thinking the speaker/writer may be trying to influence. See Levinson (1988:174).
} 
approve of its fans' behavior. By using hearer-oriented ADs, he invokes a shared experience with his followers and appeals to their shared membership in order to get them to adopt the same stance toward the Al-Ahli fans and align positively with him.

\begin{tabular}{|c|c|c|c|}
\hline $\begin{array}{l}\text { yd`ahik-ni: } \\
\text { he.entertain-me }\end{array}$ & $\begin{array}{ll}\text { 1-mufaz3ic } & \text { 1-Pahala:wi: } \\
\text { the-fan } & \text { the-Ahli }\end{array}$ & $\begin{array}{ll}\text { Pilli: } & \text { yitfalsaf-lak } \\
\text { who } & \text { philosophize- }\end{array}$ & you.D \\
\hline w-kann-o & mudarrib , & w-yinti?id-lak & Pereira \\
\hline and-as.if-him & not.only.that & and-criticize-you.D & Pereira \\
\hline
\end{tabular}

Topic/affectee-oriented ADs serve a different pragmatic function. They portray their referent as a salient element in discourse and as an individual who has been or will be affected positively or negatively by an event. Consider the tweet in (7), for example; it talks about a woman who was betrayed by a man she trusted. The optional dative -la: 'her' portrays the woman as negatively affected by the behavior of that man. Similarly, -la: 'her' in (4) above portrays its referent as (dis)pleased or (dis)satisfied by ћanna: 's behavior.

$\begin{array}{llll}\text { mSatra } & \text { Pammanit-lo } & \text { sara?-la: } & \text { Jabe:b-a: } \\ \text { poor.woman } & \text { she.trusted-him.D } & \text { he.stole-her.D } & \text { youth-her } \\ \text { w-harab } & \text { min mas?u:li:t-o } & \text { tarak-a: } & \text { li-l-Padar } \\ \text { and-ran.away } & \text { from } & \text { responsibility-his } \quad \text { he-left-her } & \text { to-the-destiny }\end{array}$

'Poor woman, she trusted him, he stole [her] her youth and ran away from his obligations toward her. He left her to her fate.'

$$
\text { تركا للقدرالحرية معتره امنتلو سرقلا شبابا وهرب من مسؤوليته }
$$

An $\mathrm{AD}$, not unlike other interpersonal pragmatic markers, may receive alternative interpretations in different contexts. For example, an AD that refers to the hearer may be interpreted as a hearer-oriented AD in one context, but it may serve as a topic/affectee-oriented $\mathrm{AD}$ in another context. Consider -lik 'you' in (4) above; in a context where the addressee is

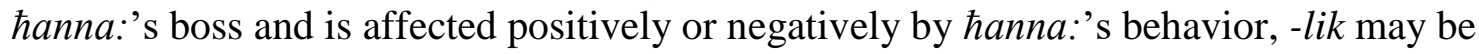
interpreted as a topic/affectee-oriented instead of a hearer-oriented AD.

Now we turn to subject-oriented ADs. These reference the subject and are generally used to express the speaker's stance toward an event as insignificant when evaluated against her/his expectations of the subject. They may also be used to portray an event as uncostly compared to the reward it may bring the subject. For example, by using a subject-oriented AD, the speaker in (4) judges the half hour or so of work as insignificant. From the speaker's perspective, hanna: 'John' could have worked for a longer period of time. Consider (8) as an additional example. The utterance is taken from a Lebanese TV talk show about social problems entitled ?aћmar bi$l$-xat ${ }^{\varsigma} l$-ৎari: $d^{\varsigma}$ 'a red line with a thick stroke.' A father whose son was raped at a very young age expresses his pain. When he is asked why he has chosen to come forward, he explains that he wants to offer advice to parents to be very careful with their children. He goes on to explain that it is no longer safe for children to play outdoors ... not even for an hour. He uses a subjectoriented AD to mark the one hour as a minimal duration when evaluated against the amount of outdoor playtime that children should be allowed to engage in. 


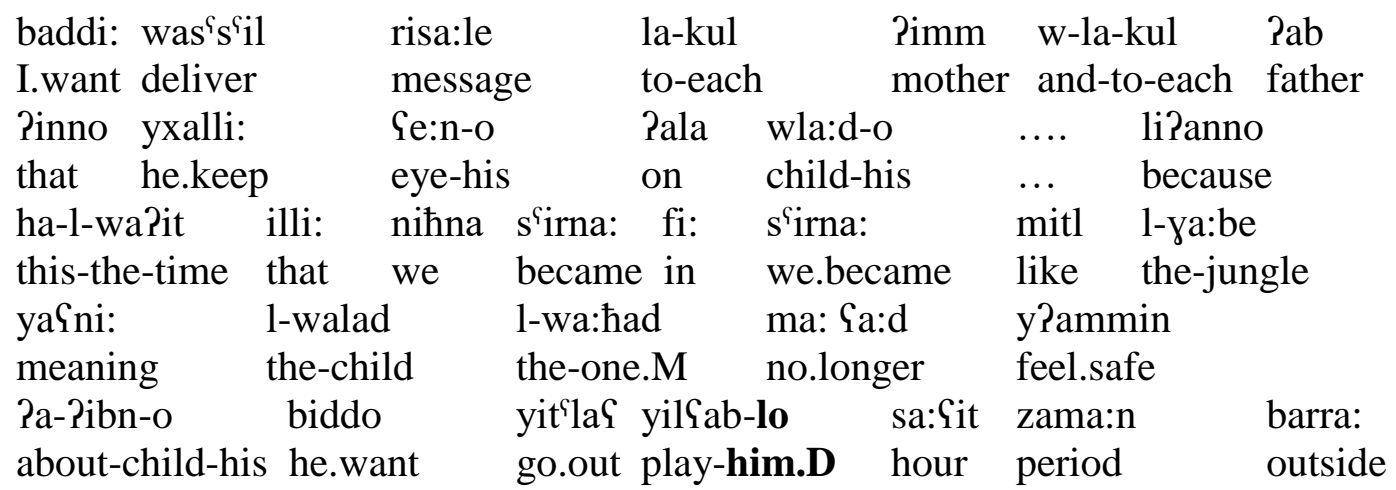

'I want to deliver a message to every mother and every father. Keep an eye on your child because our world now has become like a jungle. One can no longer guarantee that his child will be OK if he wants to play [him] for a short while outside.'

One requirement of subject-oriented $\mathrm{AD}$ constructions is to contain an adverb or an indefinite object in the form of a vague measure (Al-Zahre and Boneh 2010, 2016; Haddad 2014, 2018). The absence of a vague measure of this form leads to ungrammaticality. In (4) and (8), the expressions sa:Sit zama:n 'about an hour' and $f i$ : $n i s^{\varsigma}$ se: $\{a$ 'about a half hour' satisfy this requirement. Without these expressions, (4) and (8) would be ungrammatical unless the dative is also deleted.

We saw earlier that the same AD may serve alternative functions. For example, the same AD may be interpreted as speaker or topic/affectee oriented depending on the context. Haddad (2019) points out that subject-oriented ADs do not show the same flexibility. If an AD refers to the subject, it may only be interpreted as a subject-oriented $\mathrm{AD}$. To illustrate, consider the four examples in (9); (9b) shows that an $\mathrm{AD}$ referencing the subject is only possible in the presence of an indefinite object in the form of a vague measure. In the absence of such a vague measure, one would expect a first-person $\mathrm{AD}$ like the one in $(9 \mathrm{c})$ to serve as a speaker-oriented $\mathrm{AD}$, but it does not; the ungrammaticality of $(9 \mathrm{c})$ is evidence that an $\mathrm{AD}$ that refers to the subject may only serve as a subject-oriented AD. Finally, (9d) shows that a definite object does not render the AD construction grammatical either.
a. Pakalna:
we.ate
'We ate.'
b. Pakalne:-Ina: li?me
we.ate-us.D a.bite
'We ate [us] a bite (an insignificant amount considering what we could eating).'
c. * Pakalne:-Ina: we.ate-us.D
Intended meaning: 'We ate (and that is unacceptable).'
d. * Pakalne:-Ina: l-ba?le:wa / ha-l-ba?le:wa we.ate-us.D the-baklava / this-the-baklava
Intended meaning: 'We ate the baklava/this baklava (the event is insignificant).'

Haddad (2019) explains why subject-oriented ADs have this special status. He analyzes ADs as high applicatives that merge above $\nu \mathrm{P}$ (Boneh and Nash, 2010; Jouitteau and Rezac, 2007; McGinnis, 2001; Roberge and Troberg, 2009). Drawing on Sigurðsson and Maling's (2010) and Sigurðsson's (2014) Context-Linked Grammar, he further maintains that ADs as referential 
material determine their referent via a valuing relation with elements in the left periphery, which Sigurðsson and Maling call edge linkers and which include speakers, hearers, topics, and subjects. Edge linkers, in turn, scan the context for matching referents in order to determine their identities, as (10) illustrates. This is not unlike Zanuttini's (2008) context-to-content approach. According to Zanuttini, a jussive head passes on its second person specification to the subject, which explains why the imperative subject must be the addressee; however, the identity of the addressee is determined in the context of utterance.

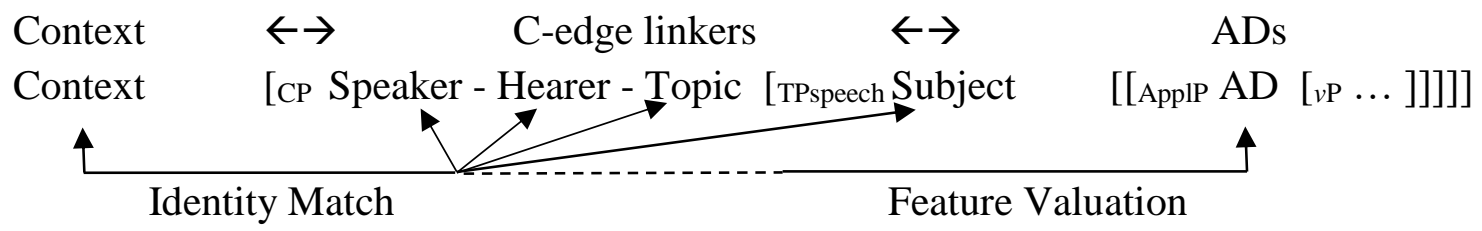

Drawing on Uriagereka (2003) and Chomsky (2004), Haddad (2014, 2019) argues that ADs as applicatives start out as adjuncts in a separate plane or dimension as in (11).

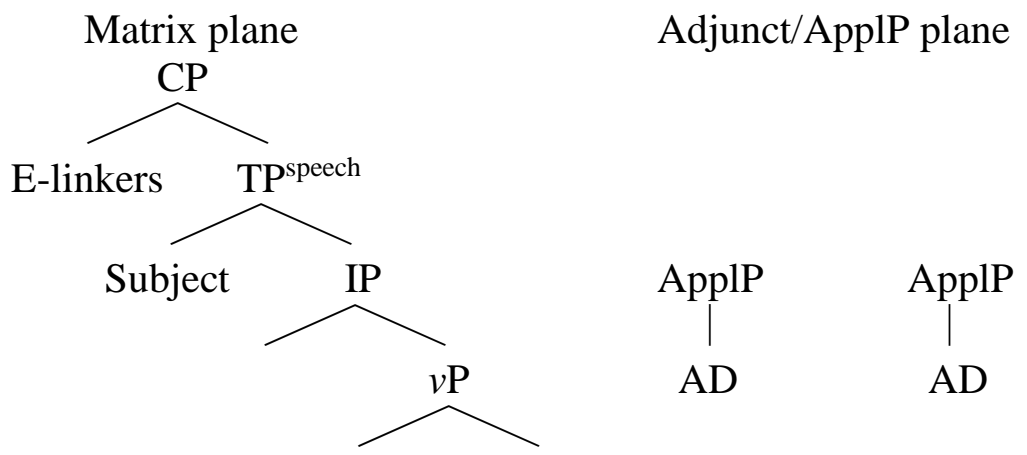

Under this analysis, an AD enter the computation with a valued discourse feature (e.g., subject, speaker, hearer) and unvalued phi features. It probes the matrix clause for an element that may value its phi features. If the valued discourse feature is [Subject] as in (12), the AD identifies the subject as a goal as soon as the subject merges in $\mathrm{Spec}, v \mathrm{P}$ of the matrix clause. The derivation draws on Branigan's (2011) Provocation. Under this analysis, the unvalued phi features on the AD are provocative in the sense that they are not simply satisfied by finding a goal with matching features, they also require that a copy be made of that goal. As a result, the subject copies and sideward moves to Spec,ApplP, as (13) illustrates. Once the phi features of the AD are valued, it merges cyclically with matrix $v \mathrm{P}$, as (14) demonstrates. The projection of IP and the head movement of the AD follow in (15), allowing the dative to cliticize to the verb.

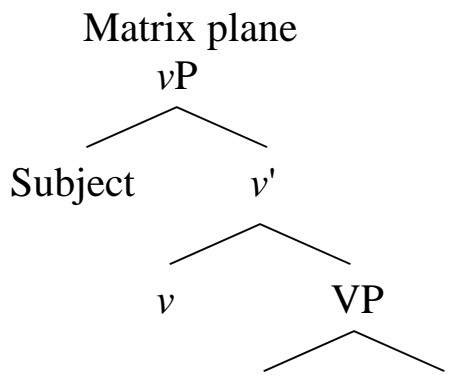

Adjunct/ApplP plane

ApplP

$\mathrm{AD}$

[Discourse: Subject]

[Phi: 


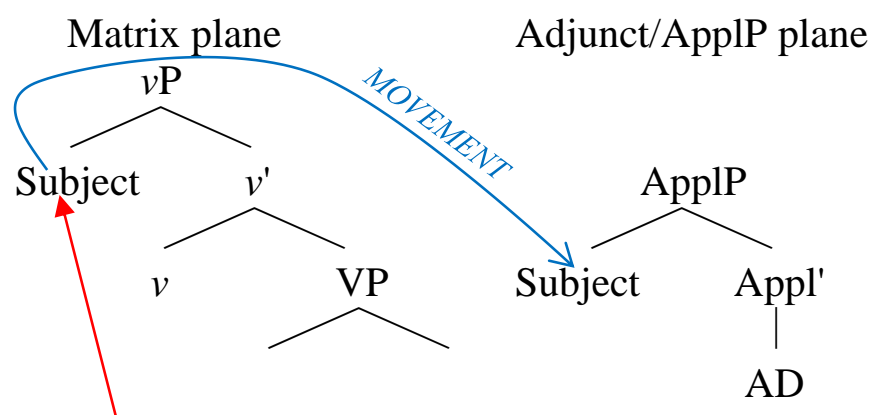

[Discourse: Subject]

[Phi:

PROVOCATION

(14)

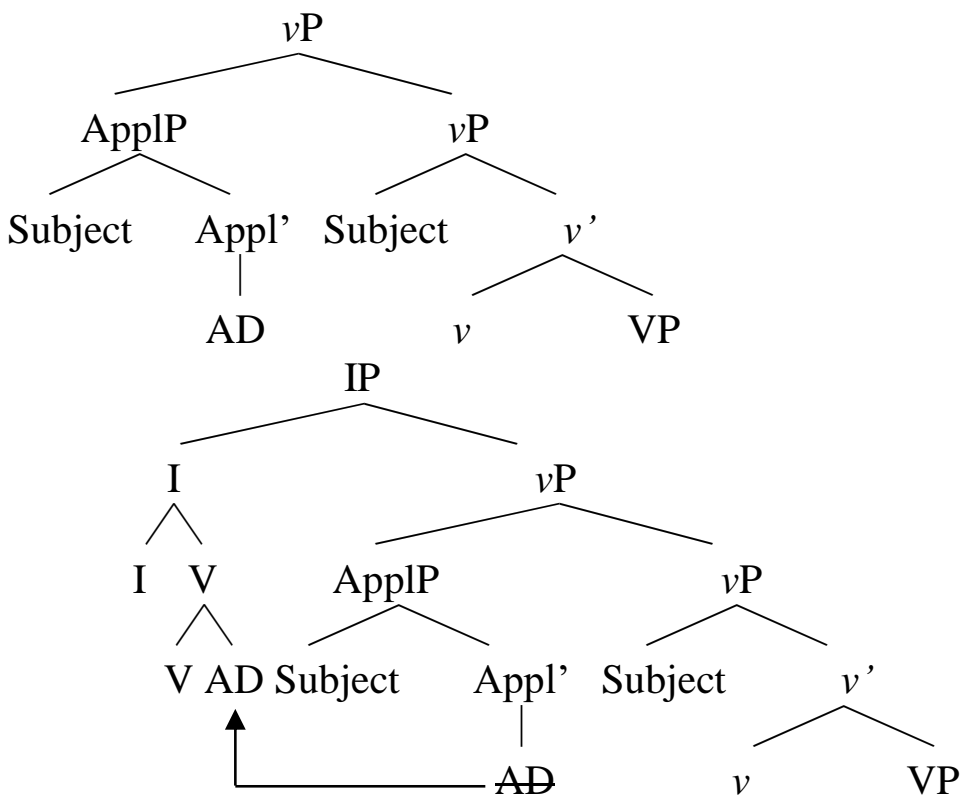

According to Haddad (2019), cyclic merge of adjuncts like ApplPs takes priority over countercyclic merge and must take place whenever possible in order to satisfy the Extension Condition as stated in Chomsky 1993. Countercyclic merge only happens as a last resort if the discourse feature of the $\mathrm{AD}$ targets an element in the left periphery; e.g., speaker or hearer. This is so because the $\mathrm{AD}$ has to wait until $\mathrm{CP}$, along with the speaker or hearer as an edge linker, has projected in the Matrix plane before it is able to find a syntactic object with a matching discourse feature. As (16) illustrates, only then will the $\mathrm{AD}$ be able to have its phi features valued and undergo merge with the Matrix clause. By the time $\mathrm{CP}$ projects in the Matrix plane, however, the only available type of merge for ApplP is counter-cyclic merge.

On occasion, the AD may enter the computation with a [Speaker] or [Hearer] discourse feature, but it may be tricked by a matching subject instead. Consider (17). The AD has the discourse feature [Hearer]. At the same time, a subject with a second-person specification merges in Spec, $\nu \mathrm{P}$ of the matrix clause. As ApplP scans the matrix clause for an element with matching features, it spots the subject as an appropriate goal. The derivation proceeds as in (18), which is similar to the derivation of the construction in (13) above. By the time, CP projects, making the hearer in the left periphery available for the probe of any potential $\mathrm{AD}$, it is already 
too late. The AD has already identified the hearer earlier, and the hearer happened to coincide with the subject.
Matrix plane
Adjunct/ApplP plane

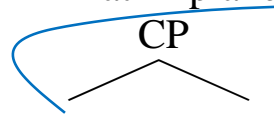

\section{Speaker/Hearer TP}
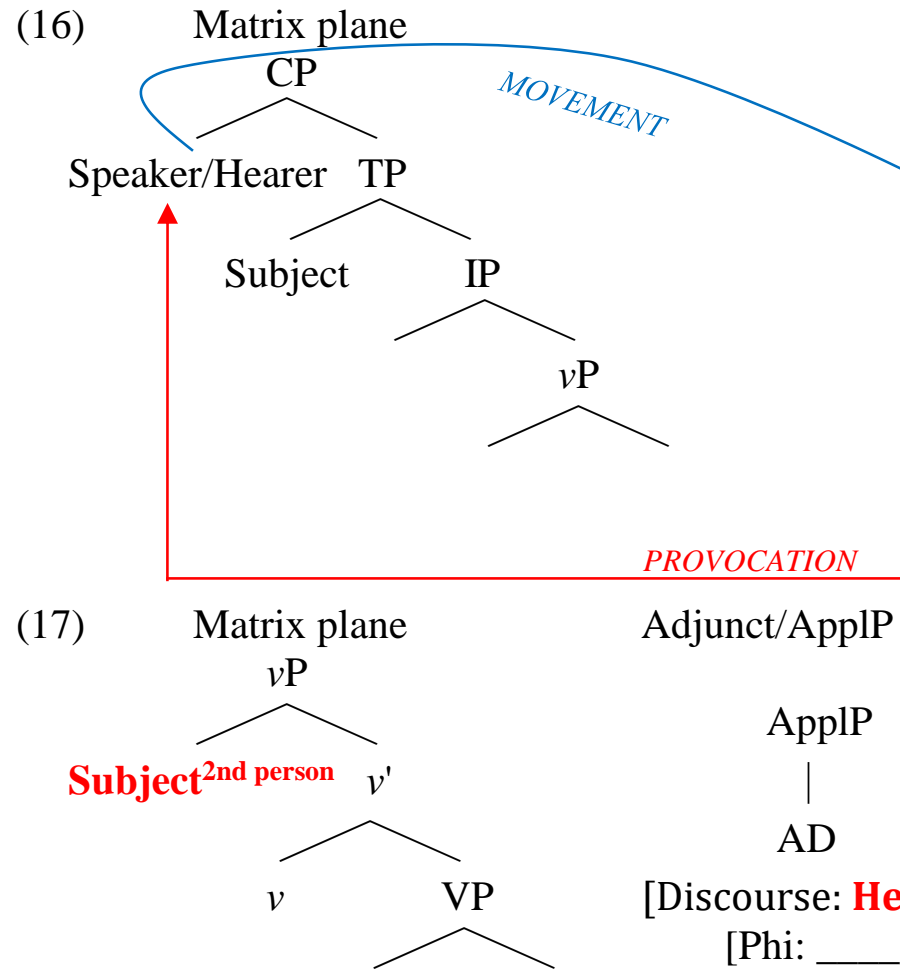

PROVOCATION

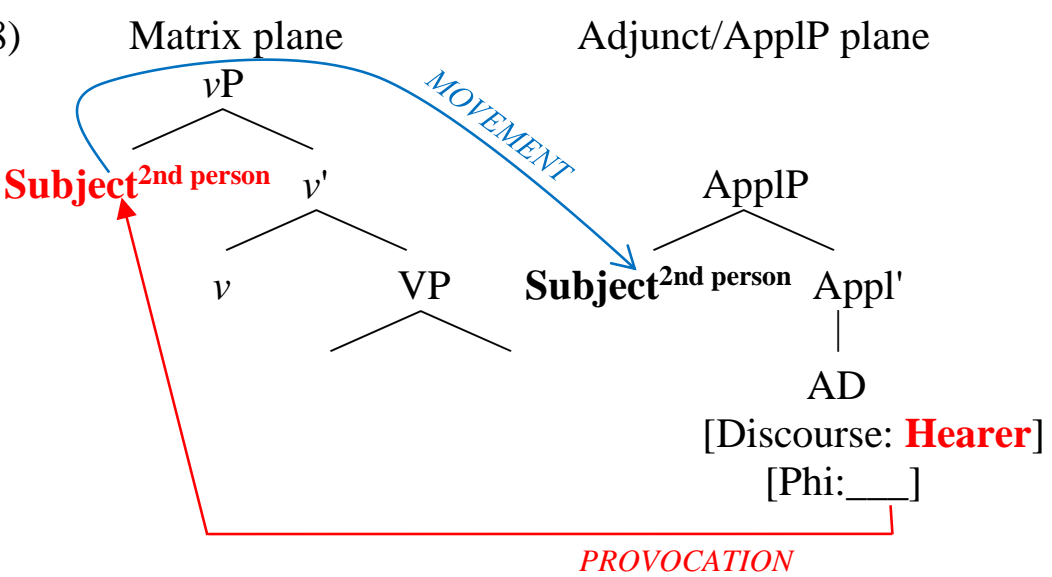

Haddad's analysis explains why an AD with the discourse feature [Hearer] in a structure like (17) with a second-person subject may only be interpreted as subject oriented and why a hearer-oriented interpretation is not available. In the following section, we will see that ADs in imperative clauses may defy this restriction and that the reason may be attributed to the special syntactic status of the imperative subject.

3. Attitude datives and the syntax of addressee in imperative clauses. If Zanuttini's (2008) account of the syntax of addressee in imperative clauses and Haddad's $(2014,2019)$ analysis of the syntax of ADs in Levantine Arabic are on the right track, an important prediction emerges: an AD may receive a hearer-oriented interpretation in an imperative clause although its referent coincides with the referent of the subject. The rest of this section shows that this prediction is 
borne out, giving further credence to Zanuttini's analysis. More precisely, it will show that imperative clauses, unlike other types of clauses, create an environment that allows ADs with the discourse feature [Hearer] to be interpreted as subject oriented or hearer oriented. This reading is available despite the fact that the subject of an imperative clause is also the hearer. ${ }^{3}$

Under Zanuttini's account, the imperative subject enters the computation with gender and number but no second-person features. The second-person specification only becomes available when the jussive phrase merges in the left periphery. Therefore, in an imperative clause, an AD with the discourse feature [Hearer] may not identify the imperative subject as an addressee and thus as a potential goal until CP/JussiveP projects. By then, both the subject and the hearer are available as potential goals, as (19) demonstrates.

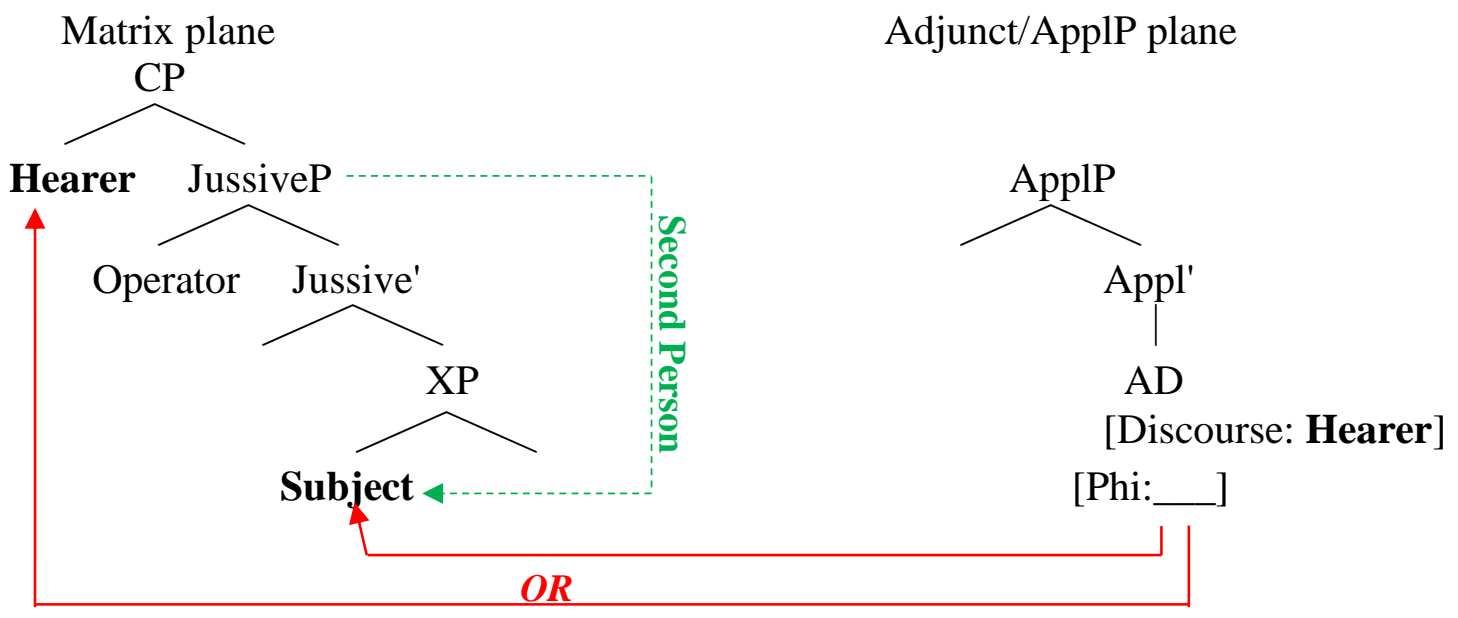

To illustrate, consider the imperative clauses (20) through (22). The ADs in these constructions behave as expected; they display a second-person specification. Since imperative subjects eventually acquire a second-person feature as well, it should be possible for the ADs to identify them as goals, and in fact they do. In (20), the tweeter gives a piece of advice to a follower who is sleep-deprived because she has been studying for an exam. He suggests that she get a couple of hours of sleep. The AD expresses the stance that the cost of two to three hours of sleep is minimal compared to the reward of getting rested and ready to study more.

$$
\begin{aligned}
& \text { na:mi:-lik sa:Ste:n tla:te w-rzaSi: kamli: } \\
& \text { sleep-you.D two.hours three and-return continue } \\
& \text { 'Take [you] a two- or three-hour nap and then continue (studying),' } \\
& \text { sama2azz@ بالتوفيق ان شاء الله ..., ناميلك ساعتين تلات }
\end{aligned}
$$

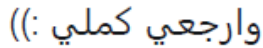

In (21), the tweeter mocks a follower who keeps posting pictures of herself on Instagram. He suggests that she should try keeping one picture to herself, with the AD expressing the stance that not posting one picture on Instagram is an insignificant feat and thus should not be difficult to accomplish.

\footnotetext{
${ }^{3}$ It is also possible for an $\mathrm{AD}$ to enter the computation with the discourse feature [Subject], and the subject may happen to have first- or second-person features. This scenario is not problematic for our purposes. The issue here is that even if the speaker intends to use a hearer-oriented AD in a construction with a second-person subject (or a speaker-oriented AD in a construction with a first-person subject), s/he will not be able to do so.
} 


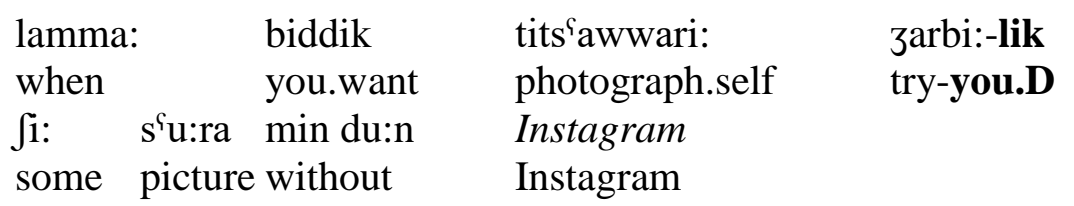

'When you want to take a picture of yourself, try [you] to take one without posting it on Instagram.'

$$
\text { لما_بدك تتصوري جربيلك شو صورة من دون إنستغرام \#\# }
$$

Example (22) is a comment on the website of an online newspaper called dunya: l-wat'an 'The Voice of the Homeland.' The commenter is a Muslim man providing advice to a Muslim woman who would like to fast during the holy month of Ramadan but finds fasting the whole month very difficult. He suggests that she should try to fast for a couple of days first. The writer uses an AD to imply that two days is an insignificant amount of time and thus should be doable.

$\begin{array}{lll}\text { zarbi:-lik } & \text { ts } \varsigma^{\varsigma} \text { umi:-lik } & \text { yawme:n } \\ \text { try-you.D } & \text { fast-you.D } & \text { two.days }\end{array}$

'Try [you] fasting [you] for a couple of days.'

https://www.alwatanvoice.com/arabic/comments/show/353997.ht

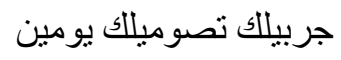

Note that each of these examples contains a vague measure: sa:Ste:n tla:te 'two to three hours' in (20); fi: $s^{\varsigma} u$ :ra 'some picture' in (21); yawme:n 'a couple of days' in (22).

Now consider the imperative clauses in (23) through (29). All these are instances of heareroriented $\mathrm{AD}$ constructions. This is so despite the fact that the referent of the ADs coincides with the referent of the imperative subject. The subject-oriented reading is not available for these examples. The reason is that none of them contains an indefinite object or an adverb that functions as a vague measure. Instead, each utterance contains a definite object referring to a specific entity, individual, or behavior. In some cases, an implied object is also possible; e.g., (26). Subject-oriented AD constructions allow neither a definite object nor an implied one; see (9). The tweets in (23) through (26) are examples of the most frequent imperative clauses with hearer-oriented ADs. Such clauses normally contain one of the following verbs: sma: $\mathcal{Y}$ 'listen,' fu:f 'see/look,' or $x o: d$ 'take.' They are used to draw the hearers' or reader's attention to something negative; that could be an event, a behavior, an object, or an individual that the contributor finds shocking, outrageous, disappointing, or negatively entertaining. Similarly to other hearer-oriented $\mathrm{AD}$ constructions, the hearer-oriented $\mathrm{ADs}$ in these examples are employed by the contributor (e.g., speaker, tweeter) to invoke a shared experience with her or his hearers or readers and to appeal to a shared membership in order to get them to adopt the same stance toward the behavior, object, or individual that s/he is criticizing.

$$
\text { smaGi:-lik ha-1-fha:r }
$$

listen-you.D this-the-nonsense

'Listen [you] to this nonsense. ${ }^{\text {' }}$

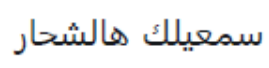

$$
\begin{aligned}
& \text { Jif-lak ha-l-Pahbal } \\
& \text { look-you.D this-the-idiot } \\
& \text { 'Look [you] at this idiot.' }
\end{aligned}
$$

شفلك هالأهبل

\footnotetext{
${ }^{4} \int \hbar a: r$ derives from a term that means 'soot'; it may be used to mean 'nonsense' or as an interjection in times of calamity or despair.
} 


\section{xid-lak}

take-you.DAT

'Listen [you] (to this nonsense/idiot)/Look (at this disaster/idiot).'

Now observe (27) through (29). Utterances like these are available, but they are not of high frequency. They normally involve verbs like zarrib 'try' and $d u:$ ? 'taste' and are used as suggestions to the hearer/reader. They highlight an entity with which the speaker or writer has had a positive experience and s/he believes the addressee would as well based on their shared experience and shared membership.

In (27), a twitter user gives advice to a follower who has the flu. He first repeats her complaint in the first person as a direct quote; he writes, 'Oh dear, I have been congested for three days, barely able to move.' He then uses an imperative clause with a hearer-oriented dative to suggest that she should try lemons as a remedy to ease the flu symptoms. Examples (28) and (29) are similar. The former is an advertisement of a Lebanese restaurant that offers mini portions of different dips and salads. The latter is a tweet. In all three examples, the writer invites the reader to try out a specific object: a remedy in (27) and a type of food in (28) and (29). By using a hearer-oriented $\mathrm{AD}$, the contributor tells the readers that s/he has found the suggestion helpful and/or rewarding and that, based on their shared experience and membership, s/he believes that they will as well. Expressions like $s^{\varsigma} a d$ Pi:-ni: 'believe me' in (27) and mu: bitfill 'isn't it amazing' in (29) emphasize the shared experience that the contributor tries to highlight and thus make the hearer-oriented interpretation more salient.

$$
\begin{array}{llll}
\text { zarbi:-lik } & \text { l-laymu:n } & \text { s}^{\varsigma} \text { adPi:-ni: } & \text { bixaffif } \\
\text { try-you.D } & \text { the-lemon } & \text { believe-me } & \text { it.relieve }
\end{array}
$$

'Try [you] lemons (as a remedy); believe me, they ease the symptoms (of the flu).'

$$
\begin{aligned}
& \text { ياعيني اليوم الثالث واناع هلحال مزكومة وهلله هلله اتحرك } \\
& \text { شوي بس جربيلك الليمون صدقيني بيخفف }
\end{aligned}
$$

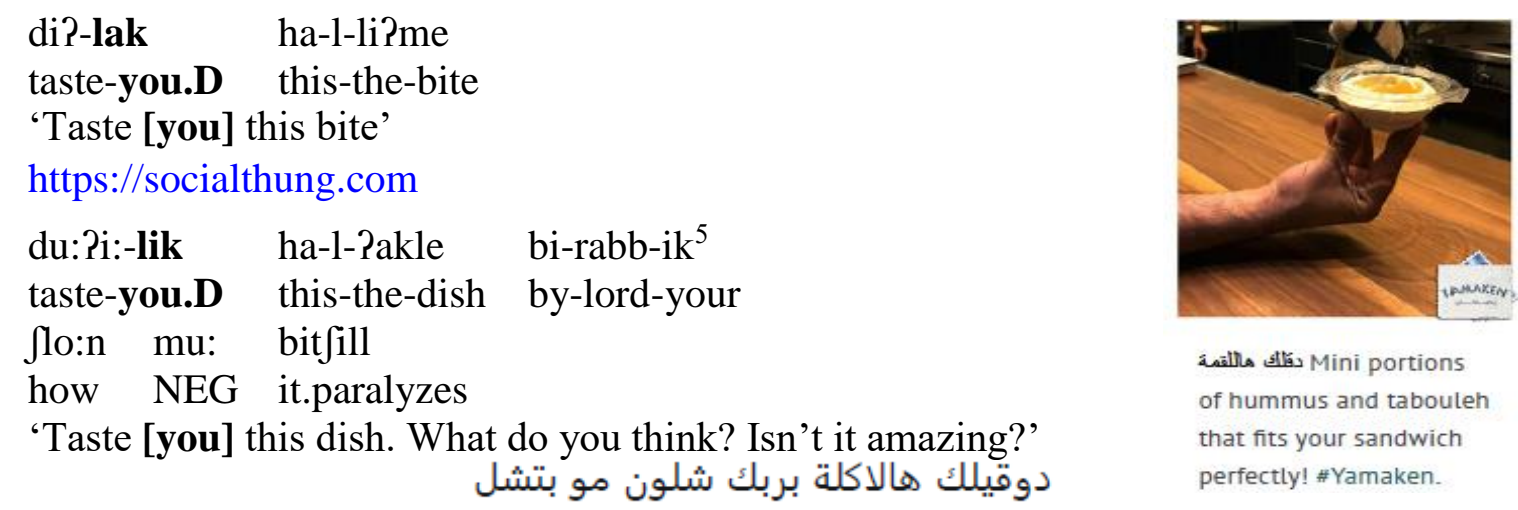

In keeping with the main functions of hearer-oriented ADs, (23) through (29) take the form of suggestions or advice that the speaker/writer has personally experienced and believes the hearer/reader may find equally useful, entertaining, shocking, etc. based on their shared

\footnotetext{
${ }^{5}$ Expressions like bi-rabb-ik 'by God/by your Lord' in (29) or Pallah 'God' in(31) are used to make an imperative sound less of a command and more of a request or suggestion. They are also used to exert friendly pressure on the hearers/readers to indulge the speaker/writer and do as they are told.
} 
experience and membership. In other words, imperative clauses with a hearer-oriented AD may not take the form of commands that only serve the speaker/writer. No such restriction applies to imperative clauses with subject-oriented ADs. While the imperative clauses with subjectoriented ADs in (20) through (22) above also take the form of suggestions or advice, example (30) from a Syrian soap opera called ba:b l-ha:ra 'the neighborhood gate' (Season 1, Episode 2) demonstrates that commands or speaker-serving imperatives are also possible. In this case, the speaker is a customer in a coffeehouse; he asks the waiter, Msallam, for a cup of tea. The speaker uses a subject-oriented AD to present the request as insignificant and thus minimally imposing on the waiter. See Haddad (2018) for more details.

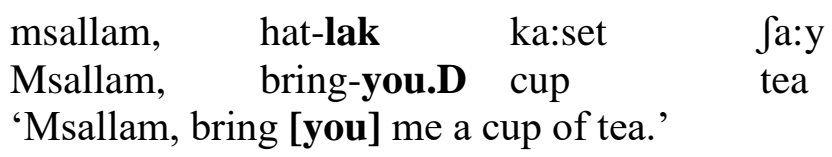

The ADs in (20) through (30) reference the imperative subject and the hearer simultaneously. In some they are interpreted as subject oriented, while in others they are interpreted as hearer oriented. It may be wondered whether an $\mathrm{AD}$ of the same type may potentially receive alternative interpretations in the same clause; that is, could the AD, say in (20), be interpreted as either subject-oriented or hearer-oriented depending on the context? As a general observation, if the imperative clause contains a vague measure in the form of an adverb or an indefinite object, the AD is more likely to be interpreted as subject oriented. In the absence of a vague measure, the subject-oriented reading becomes unavailable, and the hearer-oriented reading becomes the only available option, an option that is only available for imperative clauses. At the same time, rare examples like (31) show that alternative readings are possible. The utterance is from the Lebanese play Nazl l-suru:r 'the Surour Inn.' In this scene, a protest demonstration is taking place outside an inn in Beirut on a hot summer day. The army is using water cannons against the protesters, while the city is struggling with water shortage. A man inside the inn sarcastically states that some people join the demonstration only to take a shower. At this point, another guest asks him to open the door in order to receive a splash of water from the water cannons and cool down a little. The exchange is a criticism of the government for making bad use of the water by using it against the people instead of making it available for the people. The expression /wayy 'a little' allows the AD to be interpreted as subject oriented. In effect, the speaker would be saying that opening the door a little would be of little cost compared to the reward of cooling down on that hot summer day. At the same time, a hearer-oriented interpretation is also available. The latter reading is possible due to the fact that the speaker makes reference to a specific object (the front door of the inn). Even if fwayy 'a little' is deleted, the utterance will still be acceptable. Also, by using 'we' and 'us' in the second half of the example, the speaker makes it clear that he is not giving a self-serving command. These pronouns, along with the AD, invoke a shared experience and membership with the hearer and serve as an expression of agreement with him. After all, they both are dissatisfied with the government and its practices and think the water coming out of the water cannons could and should serve a better purpose.

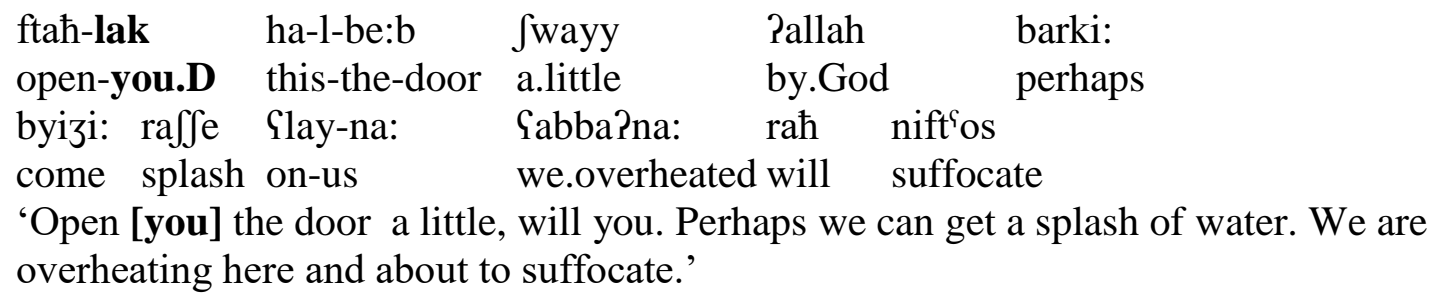


Up to this point, the claim has been that it is the special syntactic status of the imperative subject that makes the hearer-oriented interpretation of ADs available in imperative clauses. However, it may be argued that it is the semantic or pragmatic nature of imperatives rather than their syntax that allows ADs with a second-person specification to have either a subject-oriented or hearer-oriented interpretation. Negative Imperatives show that this is not the case. Unlike the imperatives we have seen so far (also known as true imperatives), negative imperatives in several languages employ verbs that show not only gender and number but also person agreement. This is why negative imperatives are also referred to as surrogate or non-true imperatives. This contrast applies to Arabic imperatives. Consider (32). Compare the true imperative form of verb 'help' in (a) with its non-true or negative imperative counterpart in (b). The latter contains a third-person feature that is absent in the former.
a. True Imperatives:
sa:Yd-i:
Paxu:-ki
help-FEM.SG brother-your.FEM
b. Non-True Imperatives:
'Help your brother.'
$\begin{array}{ll}\text { la:/ma: t-sa:Yd-i: } & \text { Paxu:-ki } \\ \text { NEG 3-help-FEM.SG } & \text { brother-your.FEM } \\ \text { 'Don't help your brother.' } & \end{array}$

The morphological realization of the second-person feature on the negative imperative verb suggests that the subject of such imperatives merges with second-person specification as well. That is, unlike in true imperatives, the subject of negative imperatives does not need to wait till JussiveP undergoes merge in order to receive a second-person feature; see Zanuttini (1996) for one explanation as to why this is the case. This also means that an $\mathrm{AD}$ with the discourse feature [Hearer] should be able to detect the non-true imperative subject as a target as early as it merges in Spec, $v \mathrm{P}$ and before the left periphery has already projected. Accordingly, only a subjectoriented but no hearer-oriented interpretation should be available for an $\mathrm{AD}$ in a negative imperative clause. This is in fact the case. No negative imperative clauses with hearer-oriented ADs like (33) are available, and none of the native speakers of Levantine Arabic whom I consulted finds such constructions felicitous or acceptable. Non-true imperatives with subjectoriented ADs, on the other hand, are readily available. The tweet in (34) is an example. It is a warning given to a friend/follower who states that she is so sleepy that she feels drunk. The tweeter warns the friend against driving under these circumstances. He uses a subject-oriented $\mathrm{AD}$ to express the sentiment that the accident, no matter how insignificant, may have major consequences.
*la: ta:xid-lak
ha-l-xabar
NEG take-you.DAT
this-the-piece.of.news
'Don't listen [you] to this piece of news.'

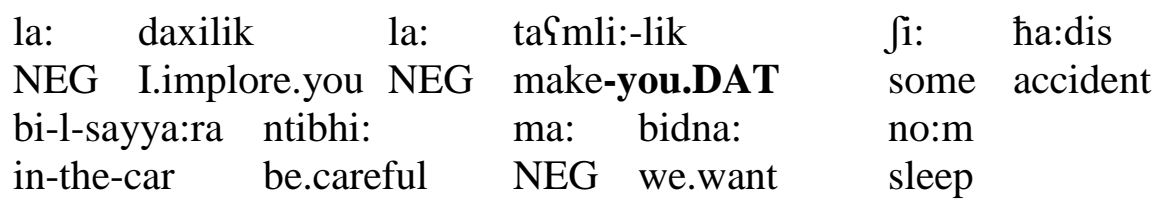

'No, please, don't drive [you] and end up having an accident. Be careful; no falling asleep behind the wheel.'

لا تعمليلك شي حادث بلسيارة انتبهي ما بدنا نوم 
Negative imperatives are more common with $? u$ : $\mathcal{C} a$ instead of $l a$ : as a negative marker. The closest equivalent to ?u: $9 a$ in English is 'don't you' when used to warn the hearer/reader (e.g., Don't you drink that; it is expired!) or sarcastically to criticize her/him (e.g., Don't you move; just stay there and do nothing!). The tweet in (35) is an example of a negative imperative with $? u: \mathcal{S} a$. The tweeter is annoyed by a follower who keeps on posting salutations to different political leaders. The tweeter uses a negative imperative with a subject-oriented AD to express his belief that any other activity that his follower may get involved in, no matter how insignificant, would be a better use of his time.

$\begin{array}{lllll}\text { inta Pu:Sa } & \text { taSmli:-lik } & \text { Ji: } & \text { Pil-o Pi:me } \\ \text { you don't.you } & \text { make-you.DAT } & \text { something to-it value } \\ \text { xalli:-k } & \text { tahiyye } & \text { la-fla:n } & \text { w-tahiyye la-Gilta:n } \\ \text { remain-you } & \text { salutation } & \text { to-this } & \text { and-salutation to-that }\end{array}$

'Don't you do [you] anything of value. Keep on tweeting salutations to this (leader) and salutations to that (leader),'

$$
\text { لعلتان اوعى تعملك شي الو قيمه خليك تحيه لفلا وتحيه }
$$

4. Conclusion. The paper starts with the observation that imperative subjects have a special status compared to the subjects of other types of clauses. Unlike other subjects, imperative subjects must coincide with the addressee. Zanuttini (2008) argues that this special status may be accounted for in the syntax. Imperative subjects enter the computation with gender and number features and are endowed with second-person specification by a jussive phrase, a projection that is unique for imperative clauses and that occupies the left periphery. The paper provides evidence from an independent phenomenon, attitude dative constructions in Levantine Arabic, in support of Zanuttini's approach. Attitude datives are subject to an interpretational restriction; if their referent coincides with the referent of the subject, they may only receive a subject-oriented interpretation. This restriction applies to ADs in all types of clauses except in imperative clauses. In an imperative clause, an $\mathrm{AD}$ that refers to the subject is not limited to a subject-oriented interpretation; a hearer-oriented interpretation is also available. The availability of alternative interpretations in imperative clauses, the paper shows, is made possible by the special syntactic representation of the imperative subject.

\section{References}

Al-Zahre, Ninsrine \& Nora Boneh. 2010. Coreferential dative constructions in Syrian Arabic and Modern Hebrew. Brill's Annual of Afroasiatic Languages and Linguistics 2. 248-282. https://doi.org/10.1163/187666310X12688137960588.

Al-Zahre, Ninsrine \& Nora Boneh. 2016. Pronominal non-core datives in Syrian Arabic. Brill's Annual of Afroasiatic Languages and Linguistics 8. 3-36. https://doi.org/10.1163/1877693000801002.

Branigan, Phil. 2011. Provocative syntax. Cambridge, MA: MIT Press.

Chomsky, Noam. 2004. Beyond explanatory adequacy. In Adriana Belletti (ed.), Structures and beyond: The cartography of syntactic structure, Vol. 3. 104-131. Oxford: Oxford University Press.

Chomsky, Noam. 1993. A minimalist program for linguistic theory. In Ken Hale \& Samuel Jay Keyser (eds.), The view from Building 20: Essays in linguistics in honor of Sylvain Bromberger. 1-52. Cambridge, MA: MIT Press. 
Christian, Donna. 1991. The personal dative in Appalachian speech. In Peter Trudgill \& J. K. Chambers (eds.), Dialects of English: Studies in grammatical variation. 13-19. London: Longman.

Haddad, Youssef A. 2014. Attitude datives in Lebanese Arabic and the interplay of syntax and pragmatics. Lingua 145. 65-103. https://doi.org/10.1016/j.lingua.2014.03.006.

Haddad, Youssef A. 2018. The sociopragmatics of attitude datives in Levantine Arabic. Edinburgh: Edinburgh University Press.

Haddad, Youssef A. 2019. Counter-cyclic merge as a last resort for adjuncts: Evidence from Levantine Arabic attitude datives. Brill's Annual of Afroasiatic Languages and Linguistics 11. 316-339. https://doi.org/10.1163/18776930-01102004.

Jouitteau, Mélanie \& Milan Rezac. 2007. The French ethical dative, 13 syntactic tests. Bucharest Working Articles in Linguistics, IX. 97-108.

Mauck, Simon. 2005. Notes on the typology of imperatives. Ms. Georgetown University.

McGinnis, Martha. 2001. Phases and the syntax of applicatives. In M-J. Kim \& Uri Strauss (eds.), Proceedings of NELS 31. 333-349. Graduate Linguistic Student Association, University of Massachusetts at Amherst.

Platzack, Christer \& Inger Rosengren. 1998. On the subject of imperatives: A Minimalist account of the imperative clause. The Journal of Comparative Germanic Linguistics 1. 177-224.

Potsdam, Eric. 1998. Syntactic issues in the English imperative. Outstanding Dissertations in Linguistics. New York: Garland Publishing.

Roberge, Yves \& Michelle Troberg. 2009. The high applicative syntax of the datives commodi/incommodi in Romance. Probus 21. 249-289. https://doi.org/10.1515/prbs.2009.008.

Rupp, Laura. 1999. Aspects of the syntax of English imperatives. Doctoral Dissertation, University of Essex.

Rupp, Laura. 2003. The syntax of imperatives in English and Germanic: Word order variation in the Minimalist framework. Basingstone: Palgrave MacMillan.

Sigurðsson, Halldor Ármann. 2014. About pronouns. Working Papers in Scandinavian Syntax 92. 66-98

Sigurðsson, Halldor Ármann \& Joan Maling. 2010. The empty left edge condition. In Michael Putnam (ed.), Exploring Crash-Proof Grammars. 59-86. Amsterdam: John Benjamins.

Uriagereka, Juan 2003. Pure adjuncts. Ms., University of Maryland.

Zanuttini, Raffaella. 1996. On the relevance of tense for sentential negation. In Adriana Belletti \& Luigi Rizzi (eds.), Parameters and functional heads: Essays in comparative syntax. 181207. New York: Oxford University Press.

Zanuttini, Raffaella. 2008. Encoding the addressee in the syntax: Evidence from English imperative subjects. Natural Language \& Linguistic Theory 26. 185-218. https://doi.org/10.1007/s11049-007-9029-6.

Zhang, Shi. 1990. The status of imperatives in theories of grammar. Doctoral Dissertation, University of Arizona.

\section{Plays - TV Shows}

ba:b l-ha:ra 'the neighborhood gate,' soap opera, Season 1, directed by Bassam al-Mulla, Aj Co. for Art Production and Distribution, 2006

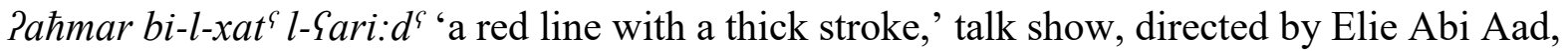
Lebanese Broadcasting Corporation International, 2008.

Nazl l-suru:r 'the Surour Inn,' play, directed by Ziad al-Rahbani, 1974. 